\title{
Influence of rs 1080985 single nucleotide polymorphism of the CYP2D6 gene on response to treatment with donepezil in patients with Alzheimer's disease
}

This article was published in the following Dove Press journal: Neuropsychiatric Disease and Treatment 26 July 2013

Number of times this article has been viewed

\author{
Aleksandra Klimkowicz- \\ Mrowiec' \\ Pawel Wolkow ${ }^{2}$ \\ Malgorzata Sado ${ }^{3}$ \\ Anna Dziubek ${ }^{3}$ \\ Joanna Pera' \\ Tomasz Dziedzic' \\ Andrzej Szczudlik' \\ Agnieszka Slowik' \\ 'Department of Neurology, \\ Jagiellonian University, School of \\ Medicine, Botaniczna, ${ }^{2}$ Department \\ of Pharmacology, Jagiellonian \\ University, School of Medicine, \\ Grzegórzecka, ${ }^{3}$ Department of \\ Neurology, University Hospital, \\ Botaniczna, Krakow, Poland
}

Background: Recent data indicate that the rs1080985 single nucleotide polymorphism of the cytochrome P450 (CYP) 2D6 gene may affect the response to treatment with donepezil in patients with Alzheimer's disease. There is also evidence that the common apolipoprotein E (APOE) polymorphism may affect the response to treatment with donepezil in Alzheimer's disease. We investigated the association between response to donepezil and the rs 1080985 single nucleotide polymorphism, the minor allele $(\mathrm{G})$ of which was previously reported to be associated with a poor response to this drug in patients with Alzheimer's disease. The common $A P O E$ polymorphism was also assessed for its relevance to the outcome of this treatment.

Methods: Analysis of CYP2D6 and $A P O E$ polymorphisms was undertaken in 88 naive Caucasian patients with Alzheimer's disease. All patients received treatment with donepezil for at least 10 months, and the response to treatment was then assessed according to the National Institute for Health and Clinical Excellence criteria.

Results: No significant differences were observed in distribution of the CYP2D6 rs 1080985 single nucleotide polymorphism or common $A P O E$ polymorphism between responders $(68.2 \%)$ and nonresponders $(31.8 \%)$ to treatment with donepezil.

Conclusion: Our results suggest that neither the CYP2D6 nor the APOE polymorphism influences the response to treatment with donepezil in a Polish population with Alzheimer's disease.

Keywords: Alzheimer's disease, CYP2D6, APOE, donepezil, pharmacogenetics, single nucleotide polymorphism

\section{Introduction}

Donepezil is currently used for symptomatic treatment of mild to moderate Alzheimer's disease. Differential response to this treatment has been observed. Interindividual genetic variants of genes responsible for drug metabolism (cytochrome P450 [CYP]) or genes associated with the pathogenesis of Alzheimer's disease (apolipoprotein E $[A P O E]$ common polymorphism) may influence the pharmacokinetic and pharmacodynamic properties of donepezil. ${ }^{1}$

After oral administration, donepezil undergoes significant first-pass metabolism by hepatic microsomal CYP enzymes to several metabolites. The CYP enzymes involved in the metabolism of donepezil are CYP3A4 and CYP2D6. ${ }^{2}$ The CYP2D6 gene (CYP family 2, subfamily D, polypeptide 6) is located on chromosome 22q13.1-13.2. This locus is highly polymorphic, with a large number of allelic variants identified and
Correspondence: Aleksandra

Klimkowicz-Mrowiec

Department of Neurology, University

Hospital, Jagiellonian University,

School of Medicine, 31-503 Cracow,

Botaniczna 3, Poland

$\mathrm{Tel}+48 \mathrm{I} 24248600$

Fax +48 I 24248626

Email aleksandra.klimkowicz@mp.pl 
resulting in different degrees of enzymatic activity. ${ }^{3}$ The $\mathrm{G}$ allele of the single nucleotide polymorphism, rs 1080985 $\left(\mathrm{C}^{-1584} \rightarrow \mathrm{G}\right)$, in the promoter region of the CYP2D6 gene, was associated with higher gene expression and greater enzymatic activity in vivo ${ }^{4,5}$ and a poor response to treatment with donepezil in Italian patients with Alzheimer's disease..$^{6-8}$

APOE is a multifunctional protein playing a key role in the metabolism of cholesterol and triglycerides, and in tissue repair and inflammation. The APOE gene is located on chromosome 19q13.2, and has three major isoforms encoded by the $\varepsilon 2, \varepsilon 3$, and $\varepsilon 4$ alleles. The $\varepsilon 4$ allele is associated with hypercholesterolemia and an increased risk of Alzheimer's disease, while the $\varepsilon 2$ allele is associated with the opposite effect. The relationship between response to donepezil and common APOE polymorphism in patients with Alzheimer's disease has been investigated in several studies, but the results are controversial.

The aim of our study was to assess the effect of the rs1080985 single nucleotide polymorphism in the promoter region of the CYP2D6 gene on the clinical outcome of treatment with donepezil in a Polish population with Alzheimer's disease. The influence of the common APOE polymorphism was also assessed for potential relevance to the outcome of treatment with a cholinesterase inhibitor.

\section{Patients and methods}

Consecutive patients admitted to the Outpatients Memory Clinic, Department of Neurology, University Hospital, Cracow, Poland, were screened for enrolment in the study. Of 361 patients, 245 were excluded because of: refusal to enter into the study $(\mathrm{n}=16)$, lack of a reliable caregiver $(n=32)$, and concomitant therapy with drugs metabolized extensively by CYP2D6 (anticholinergics, anticonvulsants, antidepressants, $\beta$-blockers, opioids, antipsychotic drugs, $\mathrm{n}=197$ ). Finally, 116 patients with Alzheimer's disease, older than 65 years at onset of the disease, and without a family history of Alzheimer's disease were included. Onset of the disease was defined as the age at which memory loss or change in behavior were first noted. The diagnosis of probable Alzheimer's disease was made according to the National Institute for Neurological and Communicative Disorders and Stroke and the Alzheimer's Disease and Related Disorders Association criteria, ${ }^{9}$ with a mild to moderate degree of disease severity. The evaluation included medical, neurologic, and neuropsychologic examinations, interviews with a close informant, laboratory testing, and computed tomography/ magnetic resonance imaging. Cognitive status was evaluated by neuropsychologic examination. ${ }^{10}$ Patients included in the study were treated with donepezil $5 \mathrm{mg} /$ day for one month, after which the dose was increased to $10 \mathrm{mg}$ a day. Follow-up visits were scheduled at months 6 and 9 of treatment with donepezil $10 \mathrm{mg}$. The response to donepezil was defined according to the criteria recommended by the National Institute for Health and Clinical Excellence. ${ }^{11} \mathrm{~A}$ responder was defined as a patient who showed improvement or no deterioration in cognition (evaluated by Mini Mental State Examination [MMSE] and the Clock Drawing Test [CDT]), and showed evidence of global improvement on behavioral or functional assessment (instrumental activities of daily living, IADL). All patients with Alzheimer's disease were Caucasian and of Eastern European descent. All participants gave their informed consent and the study was approved by the local ethics committee.

\section{DNA analyses}

Real-time polymerase chain reaction was performed using the protocol provided to assess rs1080985 single nucleotide polymorphism of the $C Y P 2 D 6$ gene. To determine the $A P O E$ genotype ( $A P O E \varepsilon 2, A P O E \varepsilon 3, A P O E \varepsilon 4$ alleles), we genotyped two single nucleotide polymorphisms (rs429358 and rs7412, National Center for Biotechnology Information) using the TaqMan assay (Applied Biosystems, Foster City, CA, USA).

\section{Statistical analysis}

Demographic data between the groups were compared by $\chi^{2}$ (gender) or $t$-test (age). The genotype frequencies were compared between responders and nonresponders using the $\chi^{2}$ test. For abnormally distributed variables, differences between the groups were tested using the Mann-Whitney $U$-test. Hardy-Weinberg equilibrium was verified for all tested populations (SAS Genetics version 9.1, SAS Institute Inc, Cary, NC, USA). Adjusted odds ratios (OR) with 95\% confidence intervals (CI) were estimated by logistic regression, controlling for APOE carrier status, gender, age, and MMSE at baseline. The level of significance was set at $P<0.05$.

We hypothesized that response to the drug would be able to be detected in two thirds of the 116 patients who entered the study, while the remaining one third of patients would show no drug response, according to response rates

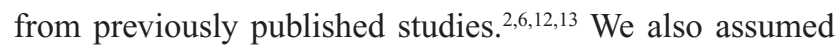
the presence of an alternative genotype (GG or GC) in $40 \%$ of subjects versus the wild-type genotype $\mathrm{CC}$ present in $60 \%$ of patients. Under these assumptions, the study has a power of $80 \%$ to detect an association between alternative 
CYP genotypes and response to the drug in patients with Alzheimer's disease at the level of significance of 0.05 if the OR of association is lower than 0.23 or higher than 3.7.

Calculated post hoc, the power in this study of 88 patients who actually completed follow-up (response to the drug detected in $68 \%$ of subjects and alternative genotype present in $39 \%$ of subjects) was $7.2 \%$ for an OR of 0.8 and $5.45 \%$ for an OR of 0.9 (lack of response to the drug detected in $32 \%$ of nonresponders and alternative genotypes present in $47 \%$ of responders).

\section{Results}

Of 116 consecutive patients (mean age $72.72 \pm 7.04$ years, 78 females [67.24\%]), 28 (mean age $73.61 \pm 7.24$ years, 18 female [64.3\%]) were excluded because they did not attend the follow-up visit at 7 or 10 months from initiation of treatment. Analysis of the rs1080985 single nucleotide polymorphism showed that 67 patients were $\mathrm{CC}$ homozygotes $(57.76 \%), 38$ were CG heterozygotes $(33.45 \%)$, and 11 were GG homozygotes $(9.48 \%)$. No differences were found between these observed frequencies and the expected Hardy-Weinberg frequencies for this locus $(P=0.12)$.

Analysis of the $A P O E$ polymorphism showed that nine patients were $\varepsilon 2 / \varepsilon 3$ heterozygotes $(7.76 \%)$, 54 were $\varepsilon 3 / \varepsilon 3$ homozygotes $(46.55 \%)$, one was a $\varepsilon 2 / \varepsilon 4$ heterozygote $(0.86 \%), 43$ were $\varepsilon 3 / \varepsilon 4$ heterozygotes $(37.07 \%)$, and nine were $\varepsilon 4 / \varepsilon 4$ homozygotes $(7.76 \%)$. No differences were found between these observed frequencies and the expected Hardy-Weinberg frequencies for this locus $(P=0.57)$. The patients lost to follow-up did not differ significantly in age at onset of the disease, sex, MMSE, CDT, and IADL score, or CYP2D6 polymorphism when compared with the rest of the group (data not shown).

During follow-up, three patients complained of nausea and vomiting when the donepezil dose was increased to $10 \mathrm{mg}$; however, when the dose was reduced and after 2 weeks it was again increased up to $10 \mathrm{mg}$, these patients were still eligible for assessment after 6 and 9 months. Of the 88 patients who were followed up, 60 were identified as responders. There was no significant difference with regard to age, sex, or scores on the MMSE, CDT, and IADL between responders and nonresponders. The characteristics of the patients at baseline are summarized in Table 1.

The CYP2D6 and APOE polymorphisms were in HardyWeinberg equilibrium ( $P=0.12$, and $P=0.57$, respectively). No differences were found between the rs 1080985 genotype distribution in the two groups $(P=0.79$; Fisher's Exact test, Table 1). Logistic regression analysis adjusted for age, sex, MMSE score at baseline, and $A P O E$ polymorphism showed no association between CG heterozygotes $(P=0.70$, OR 0.80 ; 95\% CI 0.30-2.28) or GG homozygotes $(P=0.90$, OR 0.90; $95 \%$ CI $0.15-5.40)$ and response to treatment.

Table I Demographic and clinical characteristics of patients with Alzheimer's disease who completed the follow-up visit

\begin{tabular}{|c|c|c|c|}
\hline Characteristics & Responders $(n=60)$ & Nonresponders $(n=28)$ & $P$-value \\
\hline Age at onset of $A D^{a}$ (years) & $72.23 \pm 7.40$ & $72.86 \pm 6.10$ & 0.27 \\
\hline Age at baseline ${ }^{a}$ (years) & $74.36 \pm 7.44$ & $75.14 \pm 5.8$ & 0.16 \\
\hline Women, n (\%) & $39(65)$ & $21(75)$ & 0.35 \\
\hline IADL score ${ }^{b}$ & $12(9-12)$ & $14(\mid 1.5-17.5)$ & 0.06 \\
\hline MMSE score ${ }^{b}$ & $23(14-29)$ & $22(17-25)$ & 0.20 \\
\hline CDT score ${ }^{b}$ & $8(5-10)$ & $5.5(3-9)$ & 0.06 \\
\hline \multicolumn{4}{|l|}{ APOE polymorphism } \\
\hline $2 / 3, \mathrm{n}(\%)$ & $4(6.66)$ & $3(|0.7|)$ & 'OR $0.83,95 \% \mathrm{Cl} 0.33-2.0 \mathrm{I}, P=0.66$ \\
\hline $3 / 3, \mathrm{n}(\%)$ & $29(48.34)$ & II (39.28) & ${ }^{\mathrm{d} O R} 0.69,95 \% \mathrm{Cl} 0.28-1.72, P=0.43$ \\
\hline $2 / 4, n(\%)$ & I (7.67) & & eOR $0.73,95 \% \mathrm{Cl} 0.28-1.89, P=0.52$ \\
\hline $3 / 4, n(\%)$ & $21(35)$ & $13(4.6)$ & fOR $0.63,95 \% \mathrm{Cl} 0.13-3.10, P=0.42$ \\
\hline 4/4, n (\%) & $5(8.34)$ & I (3.57) & \\
\hline \multicolumn{4}{|l|}{ rsI080985 SNP } \\
\hline GG, n (\%) & $6(10 \%)$ & $2(7.14 \%)$ & $\begin{array}{l}\text { OR I.44, } 95 \% \text { Cl 0.26-7.65, } P=0.67 \\
\text { (dominant G allele) }\end{array}$ \\
\hline CG, n (\%) & $22(36.7 \%)$ & 9 (32.14\%) & $\begin{array}{l}\text { OR } 0.6 \mathrm{I}, 95 \% \mathrm{Cl} 0.23-\mathrm{I} .57, P=0.5 \mathrm{I} \\
\text { (dominant } \mathrm{C} \text { allele) }\end{array}$ \\
\hline CC, n (\%) & $32(53.3 \%)$ & $17(60.7 \%)$ & $\begin{array}{l}\text { OR } 0.76,95 \% \mathrm{Cl} 0.38-\mathrm{I} .60, P=0.50 \\
\text { (additive model) }\end{array}$ \\
\hline
\end{tabular}

Notes: a Mean \pm standard deviation; ${ }^{b}$ mean, interquartile range; 'genotype with $\varepsilon 4$ allele versus other genotype; ${ }^{d}$ genotype with $\varepsilon 4$ or $\varepsilon 2$ allele or versus $\varepsilon 3 \varepsilon 3$ genotype; egenotype with $\varepsilon 4$ allele versus $\varepsilon 3 \varepsilon 3$ genotype; fgenotype with $\varepsilon 2$ allele versus $\varepsilon 3 \varepsilon 3$ genotype; single nucleotide polymorphism.

Abbreviations: AD, Alzheimer's disease; CDT, Clock Drawing Test; Cl, confidence interval; IADL, instrumental activities of daily living; SNP, single nucleotide polymorphism; OR, odds ratio; MMSE, Mini Mental State Examination; APOE, apolipoprotein E. 


\section{Discussion}

The variable therapeutic response to donepezil observed in patients with Alzheimer's disease may be caused by differences in the efficacy of cholinesterase inhibitors resulting from individual genetic variation in genes that influence the pharmacokinetic and pharmacodynamic properties of this drug. Identification of specific genetic polymorphisms associated with a good response to treatment with donepezil would allow an individually designed approach to therapy for patients with Alzheimer's disease.

To date, over 20 studies have investigated the relationship between responsiveness to cholinergic therapy and common $A P O E$ polymorphism. In general, their results can be divided into two groups, ie, those showing no effect of $A P O E$ status on response to treatment and those showing that patients with the $\varepsilon 4$ allele had a better response to treatment than others. ${ }^{13-18}$ Only two studies showed a better response to treatment in patients with Alzheimer's disease not carrying the $\varepsilon 4$ allele of the $A P O E$ gene..$^{19,20}$ The studies showing response to treatment had a longer observational period (12-36 months) than those not finding such an association (3-12 months). ${ }^{13,17,18}$

Two studies that analyzed the interaction between $A P O E$ status and rs1080985 did not find a direct interaction between $A P O E$ and $C Y P 2 D 6$ polymorphisms. ${ }^{7,8}$ In one of these studies, a marginal significance for frequency of the $A P O E \varepsilon 4$ and $\mathrm{rs} 1080985 \mathrm{G}$ allele was found, but an independent effect of $A P O E \varepsilon 4$ on response to donepezil was not found. ${ }^{8}$ In our study, $A P O E \varepsilon 4$ was not significantly associated with the therapeutic response to donepezil. None of the three studies supported the hypothesis of a direct interaction between $A P O E$ and CYP2D6 polymorphisms on response to treatment with donepezil.

Factors influencing the response to donepezil were evaluated in a few studies and yielded inconsistent results. Darreh-Shori et al showed better therapeutic results after 2 years of treatment, in patients who had an increased donepezil concentration in blood and cerebrospinal fluid. ${ }^{21}$ However, a study by Yuan-Han et al showed that patients treated with donepezil who did not respond to the drug after 6 months had a higher plasma concentration of donepezil. To explain these inconsistent results, a therapeutic window in the treatment of Alzheimer's disease by donepezil was postulated; an increased concentration of the drug may not improve cognitive and global function, but may induce clinical tolerance that may lead to a poor therapeutic response. ${ }^{13,22}$
The plasma concentration of donepezil is dependent on CYP2D6 polymorphism. A number of allelic variants causing either absent, decreased, or increased enzymatic activity have been described, ${ }^{3}$ allowing for categorization of the populations into three groups, ie, poor metabolizers, extensive metabolizers, and ultrarapid metabolizers. The efficacy of donepezil after 3 months of treatment in 42 Italian patients with Alzheimer's disease ${ }^{23}$ and in another Italian population of 57 patients with Alzheimer's disease after 6 months $^{6}$ showed that poor metabolizers are better responders. However, a study by Chianella et $\mathrm{al}^{24}$ evaluating 92 patients after one year of treatment with donepezil reported a general tendency towards a higher frequency of faster metabolizers in responders.

The phenotypic outcome of $\operatorname{rs} 1080858\left(\mathrm{C}^{-1584} \rightarrow \mathrm{G}\right)$ in the promoter region of the CYP2D6 gene remains controversial. ${ }^{4,5}$ The influence of rs1080985 on response to treatment with donepezil was assessed in three Italian studies. ${ }^{6-8}$ The frequency of the $G$ allele was higher in nonresponders than in responders, and the presence of the $\mathrm{G}$ allele was associated with a poor response to treatment with donepezil; however, the effect size of the modulation of donepezil response was small to moderate. We were not able to replicate these results in our study. We did not find an association between the rs1080985 single nucleotide polymorphism of the CYP2D6 gene and response to treatment in a Polish population. The $G$ allele was found more often in responders than in nonresponders, but the difference was not significant.

Although data regarding the CYP2D6 polymorphism are inconclusive, they do not rule out the role of rs1080985 as a marker of response to therapy. It was suggested that another genetic variant of CYP2D6 may be in linkage disequilibrium with rs1080985 and influence the phenotypic effect of this polymorphism. ${ }^{23}$ Further, other as yet unknown factors beyond the concentration of donepezil and CYP2D6 polymorphism influencing poor therapeutic responses need to be clarified.

Genetic replication studies are important, especially in different ethnic groups, to confirm the first observation usually in small populations. So far, the results of published studies encourage continued evaluation of the role of rs1080985 polymorphism in response to treatment with donepezil in different populations.

\section{Disclosure}

The authors report no conflicts of interest in this work. 


\section{References}

1. Cacabelos R. Influence of pharmacogenetics factors on Alzheimer's disease therapeutics. Neurodegener Dis. 2008;5(3-4):176-178.

2. Cacabelos R, Llovo R, Fraile C, Fernandez-Novoa L. Pharmacogenetic aspects of therapy with cholinesterase inhibitors: the role of CYP2D6 in Alzheimer's disease pharmacogenetics. Curr Alzheimer Res. 2007;4(4): 479-500.

3. Human Cytochrome P450 (CYP) Allele Nomenclature Committee. Available from: http://www.cypalleles.ki.se/. Accessed September 4, 2012.

4. Zanger UM, Fischer J, Raimundo S, et al. Comprehensive analysis of the genetic factors determining expression and function of hepatic CYP2D6. Pharmacogenetics. 2001;11(7):573-585.

5. Gaedigk A, Ryder DL, Bradford LD, Leeder JS. CYP2D6 poor metabolizer status can be ruled out by a single genotyping assay for the $-1584 \mathrm{G}$ promoter polymorphism. Clin Chem. 2003;49(6 Pt 1): 1008-1011.

6. Seripa D, Bizzarro A, Pilotto A, et al. Role of cytochrome P4502D6 functional polymorphisms in the efficacy of donepezil in patients with Alzheimer's disease. Pharmacogenet Genomics. 2011;21(4): 225-230.

7. Pilotto A, Franceschi M, D’Onofrio G, et al. Effect of a CYP2D6 polymorphism on the efficacy of donepezil in patients with Alzheimer disease. Neurology. 2009;73(10):761-767.

8. Albani D, Martinelli Boneschi F, Biella G, et al. Replication study to confirm the role of CYP2D6 polymorphism rs1080985 on donepezil efficacy in Alzheimer's disease patients. J Alzheimers Dis. 2012;30(4): 745-749.

9. McKhann G, Drachman D, Folstein M, Katzman R, Price D, Stadlan EM. Clinical diagnosis of Alzheimer's disease: report of the NINCDS-ADRDA Work Group under the auspices of Department of Health and Human Services Task Force of Alzheimer's disease. Neurology. 1984;34(7):939-944.

10. Klimkowicz-Mrowiec A, Slowik A, Krzywoszanski L, Herzog-Krzywoszanska R, Szczudlik A. Severity of explicit memory impairment due to Alzheimer's disease improves effectiveness of implicit learning. J Neurol. 2008;255(4):502-509.

11. National Institute for Health and Clinical Excellence. Available from: http://www.nice.org.uk/nicemedia/live/13419/5361. Accessed July 2, 2013.

12. Wilkinson D, Schindler R, Schwam E, et al. Effectiveness of donepezil in reducing clinical worsening in patients with mild-to-moderate Alzheimer's disease. Dement Geriatr Cogn Disord. 2009;28(3):244-251.

13. Yang YH, Wu SL, Chou MC, Lai CL, Chen SH, Liu CK. Plasma concentration of donepezil to the therapeutic response of Alzheimer's disease in Taiwanese. J Alzheimers Dis. 2011;23(3):391-397.
14. Rigaud AS, Traykov L, Latour F, et al. Presence or absence of at least one $\varepsilon 4$ allele and gender are not predictive for the response to treatment with donepezil in Alzheimer's disease. Pharmacogenetics. 2002; 12(5):415-420.

15. Poirier J, Delisle MC, Quirion R, et al. Apolipoprotein E4 allele as a predictor of cholinergic deficits and treatment outcome in Alzheimer disease. Proc Natl Acad Sci U S A. 1995;92(26):12260-12264.

16. Almkvist O, Jelic V, Amberla K, et al. Responder characteristics to a single oral dose of cholinesterase inhibitor: a double-blind placebo-controlled study with tacrine in Alzheimer patients. Dement Geriat Cogn Disord. 2001;12(1):22-32.

17. Aerssens J, Raeymaekers P, Lilienfeld S, et al. APOE genotype: no influence on galantamine treatment efficacy nor on rate of decline in Alzheimer's disease. Dement Geriatr Cogn Disord. 2001;12(2): 69-77.

18. Babic T, Mahovic Lakusic D, Sertic J, et al. ApoE genotyping and response to galantamine in Alzheimer's disease - a real life retrospective study. Coll Antropol. 2004;28(1):199-204.

19. Borroni B, Colciaghi F, Pastorino L, et al. ApoE genotype influences the biological effect of donepezil on APP metabolism in Alzheimer disease: evidence from a peripheral model. Eur Neuropsychopharmacol. 2002;12(5):195-200.

20. Choi SH, Kim SY, Na HR, et al. Effect of ApoE genotype on response to donepezil in patients with Alzheimer's disease. Dement Geriatr Cogn Disord. 2008;25(5):445-450.

21. Darreh-Shori T, Meurling L, Pettersson T, at al. Changes in the activity and protein levels of CSF acetylcholinesterases in relation to cognitive function of patients with mild Alzheimer's disease following chronic treatment with donepezil. J Neural Transm. 2006;113(11): 1791-1801.

22. Sramek JJ, Cutler NR. RBC cholinesterase inhibition: a useful surrogate marker for cholinesterase inhibitor activity in Alzheimer disease therapy? Alzheimer Dis Assoc Disord. 2000;14(4):216-227.

23. Varsaldi F, Miglio G, Scordo MG, et al. Impact of the CYP2D6 polymorphism on steady-state plasma concentrations and clinical outcome of donepezil in Alzheimer's disease patients. Eur J Clin Pharmacol. 2009;62(9):721-726.

24. Chianella C, Gragnaniello D, Maisano Delser P, et al. BCHE and CYP2D6 genetic variation in Alzheimer's disease patients treated with cholinesterase inhibitors. Eur J Clin Pharmacol. 2011;67(11): 1147-1157.
Neuropsychiatric Disease and Treatment

\section{Publish your work in this journal}

Neuropsychiatric Disease and Treatment is an international, peerreviewed journal of clinical therapeutics and pharmacology focusing on concise rapid reporting of clinical or pre-clinical studies on a range of neuropsychiatric and neurological disorders. This journal is indexed on PubMed Central, the 'PsycINFO' database and CAS.

\section{Dovepress}

The manuscript management system is completely online and includes a very quick and fair peer-review system, which is all easy to use. Visit http://www.dovepress.com/testimonials.php to read real quotes from published authors. 